\begin{tabular}{|c|c|}
\hline Title & $\begin{array}{l}\text { Short-lived ice speed-up and plume water flow captured by a VTOL UAV give insights into subglacial hydrological } \\
\text { system of Bowdoin Glacier }\end{array}$ \\
\hline Author(s) & Jouvet, Guillaume; Weidmann, Y vo; Kneib, Marin; Detert, Martin; Seguinot, Julien; Sakakibara, Daiki; Sugiyama, Shin \\
\hline Citation & $\begin{array}{l}\text { Remote Sensing of Environment, 217, 389-399 } \\
\text { https://doi.org/10.1016/ .rse.2018.08.027 }\end{array}$ \\
\hline Issue Date & $2018-11$ \\
\hline Doc URL & http:/hdl.handle.net/2115/79685 \\
\hline Type & article (author version) \\
\hline File Information & Remote Sensing of Environment 217_389-399.pdf \\
\hline
\end{tabular}

Instructions for use 


\title{
Short-lived ice speed-up and plume water flow captured by a VTOL UAV give insights into subglacial hydrological system of Bowdoin Glacier
}

\author{
Guillaume Jouvet ${ }^{\mathrm{a}}$, Yvo Weidmann ${ }^{\mathrm{a}}$, Marin Kneib ${ }^{\mathrm{a}}$, Martin Detert $^{\mathrm{a}}$, Julien Seguinot ${ }^{\mathrm{a}, \mathrm{c}}$, \\ Daiki Sakakibara ${ }^{b}$, Shin Sugiyama ${ }^{b}$ \\ ${ }^{a}$ ETHZ, VAW, Zurich, Switzerland \\ ${ }^{b}$ Institute of Low Temperature Science, Hokkaido University, Sapporo, Japan \\ ${ }^{c}$ Arctic Research Center, Hokkaido University, Sapporo, Japan
}

\begin{abstract}
The subglacial hydrology of tidewater glaciers is a key but poorly understood component of the complex ice-ocean system, which affects sea level rise. As it is extremely difficult to access the interior of a glacier, our knowledge relies mostly on the observation of input variables such as air temperature, and output variables such as the ice flow velocities reflecting the englacial water pressure, and the dynamics of plumes reflecting the discharge of meltwater into the ocean. In this study we use a cost-effective Vertical Take-Off and Landing (VTOL) Unmanned Aerial Vehicle (UAV) to monitor the daily movements of Bowdoin Glacier, north-west Greenland, and the dynamics of its main plume. Using Structure-fromMotion photogrammetry and feature-tracking techniques, we obtained 22 high-resolution ortho-images and 19 velocity fields at the calving front for 12 days in July 2016. Our results show a two-day-long speed-up event (up to 170\%) - caused by an increase in buoyant subglacial forces - with a strong spatial variability revealing that enhanced acceleration is an indication of shallow bedrock. Further, we used the Particle Image Velocimetry (PIV) method to analyze water flow from successive UAV images taken while flying over the main plume of the glacier. We found that PIV successfully captures the area of radially diverging flow of the plume, and provides information on spatial and time variability as no other remote sensing technique can. Most interestingly, the active part of the plume features pulsating water jets at the time scale of seconds, and is 1 to 5 times smaller than its visual footprint defined by the iceberg-free area. Combined with an ice flow model or a non-steady plume model, our approach has the potential to generate a novel set of input data to gather information about the depth of the bedrock, the discharge of meltwater, or the subglacial melting rate of tidewater glaciers.
\end{abstract}

Key words: Unmanned Aerial Vehicle, Structure-from-Motion photogrammetry, feature-tracking, Particle Image Velocimetry, calving glaciers, meltwater plume, ice flow

\section{Introduction}

Atmospheric warming in recent decades has caused glaciers and ice sheets to shrink 
substantially worldwide, and thus contribute to the observed global sea level rise (Pritchard et al., 2009; Joughin et al., 2010). Our ability to predict its future evolution depends not only on the accuracy of climate change projections, but also on our understanding of the combining of processes such as ice thermodynamics, mass balance, iceberg calving, ice-ocean interaction and subglacial hydrology. Among these processes, the last one is a crucial but poorly constrained process as it is extremely difficult to monitor the interior of a glacier. As an alternative, information on subglacial hydrology can be inferred from surface ice flow - whose the sliding component of fast flow is driven mostly by englacial water pressure (Sugiyama et al., 2011) - or glacier runoff.

In the case of tidewater glaciers, the discharge of meltwater into the ocean is often characterized by proglacial "plumes" (Mankoff et al., 2016) at the ocean surface next to the calving front. As the plume rises from the bottom of the glacier front, turbulent entrainment dilutes the plume with salty ocean water, decreasing their density difference until plume and fjord waters reach the same level (called neutral buoyancy), see Fig. 1. Due to the vertical momentum, the water thus mixed can continue to rise past this level and reach the ocean surface, but then plunges back downwards to regain the neutral buoyancy level as it flows away from the glacier (Carroll et al., 2015). The turbulent and turbid water flows visible at the ocean surface directly reflect the intensity of the plume. Plumes are key components of the glacial system, not only because they reflect the glacier runoff, but also because they can strongly enhance submarine melting (Rignot et al., 2010; Motyka et al., 2013), and subsequently amplify calving (Slater et al., 2017a).

Thanks to high-performance computing, and the substantial efforts made by the scientific community, the accuracy of ice flow mod- els (along with subglacial hydrology) such as Elmer/Ice (Gagliardini et al., 2013) have taken a significant step forward in the last ten years. In the meantime, parallel efforts to physically model the interaction between the ice and the ocean were made (Dinniman et al., 2016), including the modelling of plumes (Jenkins, 2011; Carroll et al., 2015; Slater et al., 2017b). The increasing sophistication of models requires new variables to be determined, and this automatically increases the need for input data, such as surface ice flow velocities in inverse ice flow modelling (Morlighem et al., 2013).

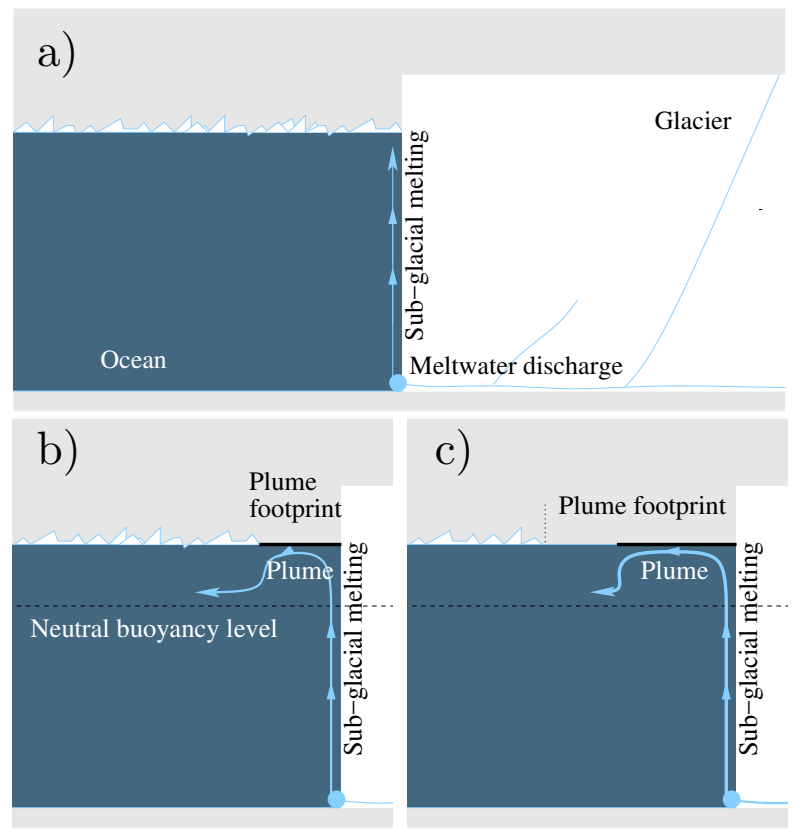

Figure 1: Schematic description of plume mechanisms at three different stages: a) the meltwater discharge is low, remains under the sea ice, and is invisible from the surface; b) the discharge is sufficient to collapse the sea ice, but only the 'active' part of the plume is free of sea ice ; c) the discharge collapses further the sea ice, leaving a footprint which is larger than its 'active' part.

Observations of ice motion reveal variations at different time scales (e.g., Bartholomew et al., 2012). These range from minute-scale velocity responses to large 
iceberg calving events (e.g., Murray et al., 2015), to hourly scale variations induced by tide (e.g., Sugiyama et al., 2015), to weekly scale ice speed-ups caused by the drainage of supraglacial lakes (Joughin et al., 1996), to multi-year-scale variations in response to glacier thinning (e.g., Pfeffer, 2007). Weekly or monthly ice flow changes can be tracked by repeated satellite images (Heid and Kääb, 2012). Orbital periods of observation satellites are usually too long to capture variations at daily or subdaily resolution. Minute-scale monitoring of the ice displacement can be done by means of expensive laser scanning (Pętlicki and Kinnard, 2016), interferometric radar (Riesen et al., 2011), or in situ GPS (Sugiyama et al., 2015). However, the ground-based remote sensing instruments have to be installed well above the glacier surface in order to obtain optimal coverage. Moreover, when this condition is fulfilled, it is a tedious task to access the site and maintain the equipment for a significant time period. The same obstacles apply to the monitoring of meltwater plumes. Due to their signature left on the ocean surface, a plume can be surveyed at a global scale by means of satellite images (Chu et al., 2009; Bartholomaus et al., 2016), or more frequently and more locally using interferometric radar or automatic cameras. For instance, Slater et al. (2017a) have tracked the visibility of a surfacing plume to infer subglacial hydrology. Conversely, How et al. (2017) determined the footprint of meltwater plumes from time-lapse imagery in order to estimate the subglacial discharge. To our knowledge, no one has ever attempted to use aerial imagery to track the flow of a meltwater plume at the ocean surface. In contrast, plumes can be monitored below the surface by conducting hydrographic in-situ measurements, i.e., conductivity-temperature-depth (Motyka et al., 2013; Mankoff et al., 2016; Stevens et al., 2016). However, this implies using heavy and costly logistics.

Unlike satellite remote sensing or in-situ observation with grounded instruments, Unmanned Aerial Vehicles (UAV) can generate frequent and high-resolution aerial glacier images with relative minor effort and at a low cost (Immerzeel et al., 2014; Ryan et al., 2015; Jouvet et al., 2017). In their review article, Bhardwaj et al. (2016) elaborate the advantages of UAVs over conventional remote sensing platforms in glaciology and examine the applications already performed in polar and alpine environments. The flight range of UAVs is a limiting factor for reaching and mapping remote and large glacial areas. Multicopter UAVs like the DJI Phantom are easy to fly without prior experience, can take off and land in confined areas. However, they have a limited operational range - usually under $10 \mathrm{~km}$ assuming low altitude flights. Small fixed-wings, such as the Ebee (sensefly.com), can double this range while remaining relatively easy to operate. On the other hand, large fixed-wing UAVs (Ryan et al., 2015; Jouvet et al., 2017) can fly higher and over much longer distances (over $100 \mathrm{~km}$ ), but require special flight training and are difficult to land in mountainous environments. For this reason, the latter are more suitable for mapping vast glacier areas (typically over $10 \mathrm{~km}^{2}$ ) more often found in polar regions. Thanks to the latest technological developments, a new generation of UAV, based on the Vertical Take-Off and Landing (VTOL) principle, is now emerging. VTOL UAVs are hybrid platforms of multicopters and fixed-wings, which combine the advantages of both since they can take off and land smoothly and accurately as a multicopter, while benefitting from the long range offered by fixed-wings. Therefore, recent progress in the use of VTOL UAVs is expected to extend the flight range for non-expert UAV users in coming years, allowing even more remote and much larger areas than ever before to be sur- 
veyed. Thus this technology is clearly suitable for glacier monitoring. To our knowledge, VTOL UAVs have never before been used for this purpose.

For this study, we used a VTOL UAV to monitor Bowdoin glacier, north-west Greenland, twice a day. More precisely, we surveyed an ice surface area of approximately $3 \mathrm{~km}^{2}$ near the calving front for 13 days in July 2016, with the aim of capturing both the glacial motion and water flow velocities of Bowdoin's main plume. This paper is organized as follows: After providing some key facts about Bowdoin Glacier, we describe the instruments and methods employed to conduct this study. Then, we present our results with regard to ice flow velocity, calving, and meltwater plume activities. In the final section, we discuss the interaction between these processes and subglacial hydrology.

\section{Study site}

Bowdoin Glacier $\left(77^{\circ} 41^{\prime} \mathrm{N}, 68^{\circ} 35^{\prime} \mathrm{W}\right.$ ) is an ocean-terminating glacier, which belongs to a network of outlet glaciers located in the north-west sector of the Greenland ice sheet. The glacier ends in the Bowdoin fjord through an approximately $3 \mathrm{~km}$ wide calving front, see Fig. 2. At the center of the calving front, the glacier is approximately 250 meter thick, grounded, and nearly at floatation (Sugiyama et al., 2015). As a consequence, the ice flow at the glacier front is highly influenced by buoyant forces, which counteract the ice weight and favour basal sliding. Ice flow is slower further upstream where the ice is thicker and thus undergoes further basal friction. Thus, the ice speed increases with proximity to the ocean, reaching 1 to $2 \mathrm{~m} \mathrm{~d}^{-1}$ at the calving front (Sugiyama et al., 2015). Since 2013, the front of Bowdoin Glacier has experienced only minor seasonal fluctuations, i.e., its advance has been compensated for by iceberg calving at the multiyear scale (Sakakibara and Sugiyama, 2018).

Between July 2013 and 2016, field measurements were carried out every summer on Bowdoin Glacier, including ice-penetrating radar and GPS surveys (Sugiyama et al., 2015; Tsutaki et al., 2016; Asaji, 2018), seismic records (Podolskiy et al., 2016), nutrient concentration measurements in the plumes (Kanna et al., 2018), automatic camera installations, the drilling of boreholes (to record internal ice deformation, englacial temperature and water pressure). Our campsite was located at the south-east edge of the glacier approximately $2 \mathrm{~km}$ upstream from the calving front, and $100 \mathrm{~m}$ north of a river which flowed from an eastern glacier snout (Mirror Glacier) towards Bowdoin Glacier, see Fig. 2, middle panel. At the beginning of July 2016, an ice-dammed lake formed at the edge of the glacier, but drained suddenly on July 6 , approximately two days after we set up our camp, see Fig. 3.

\section{Methods}

\subsection{Vertical Take-Off and Landing UAV}

During the 2016 fieldwork period, we operated a UAV from our camp to monitor the river and the calving front sites, see Figs. 2 (bottom panel) and 3. We chose the Firefly6 (https://www.birdseyeview.aero/) Vertical Take-Off and Landing (VTOL) as UAV. This is a hybrid device between a hexacopter and a fixed-wing, see Fig. 4. VTOL UAVs have the advantage of being able to take off and land vertically in confined areas as multicopters (hover flight configuration), while also flying horizontally and efficiently over long distances as fixed-wings (forward flight configuration). The disadvantage of VTOLs is that they are more sensitive than multicopters to wind in hover mode, as the wings induce some resistance, thus rendering VTOLs more vulnerable to gusts of wind. In 


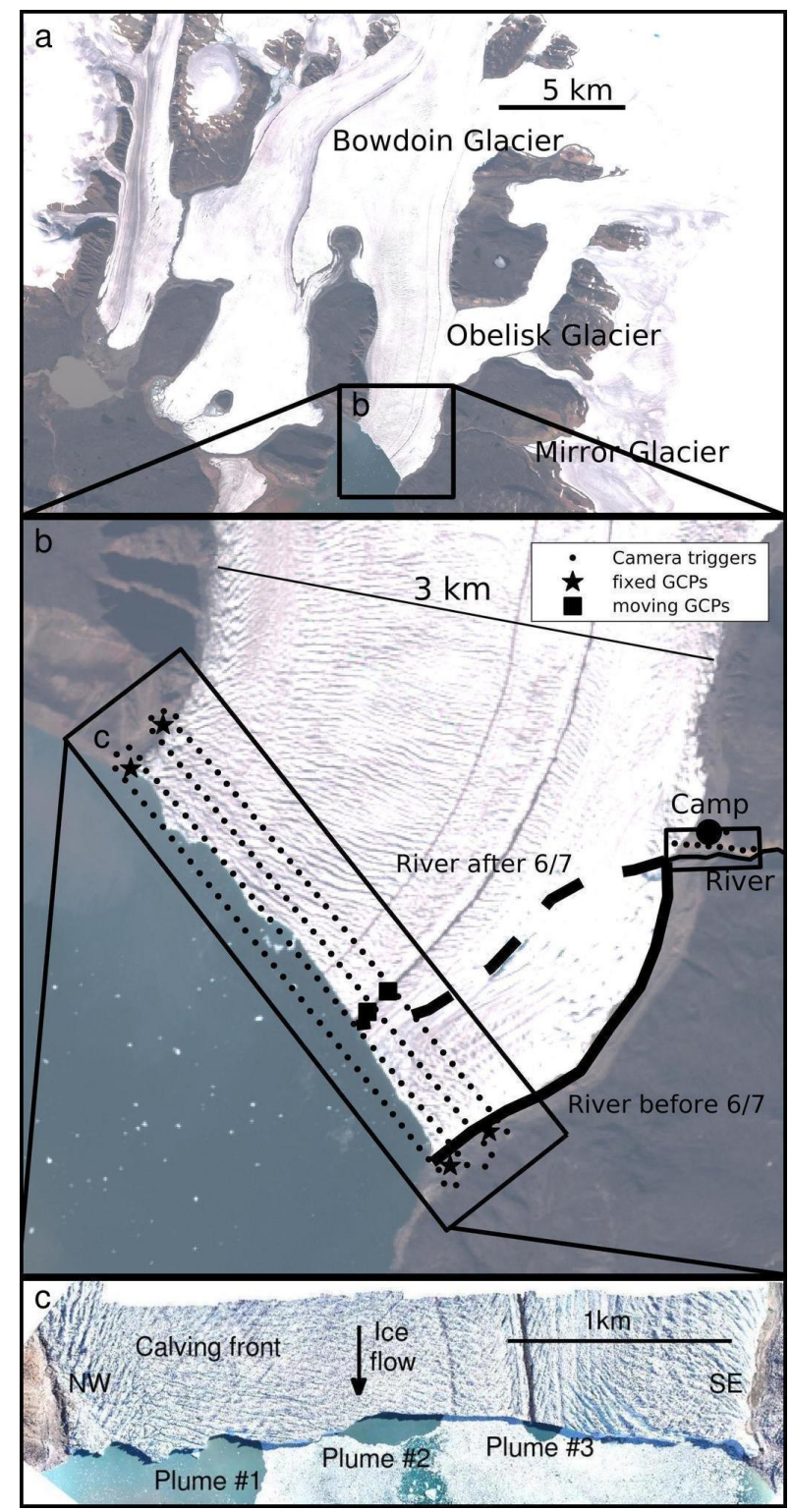

Figure 2: a) Sentinel satellite image (Copernicus Sentinel data 2016, processed with SentinelFlow) showing Bowdoin Glacier and its two catchment basins: the northern large branch and the eastern smaller one (Obelisk Glacier) on July 30, 17:29 UTC. b) Same satellite image of the terminus of Bowdoin Glacier including the two regions monitored by VTOL UAV: the calving front and the river next to the campsite. Black dots represent the horizontal locations, from where aerial images were taken by the UAV (camera triggers), while fixed and moving Ground Control Points (GCP) are indicated by black star and square symbols, respectively. The paths taken by the river before and after the lake outburst are indicated by continuous and dashed lines, respectively. c) UAV ortho-image of the calving front (July 15, 12:31 UTC), with meltwater plumes numbered from the north-west to the south-east.

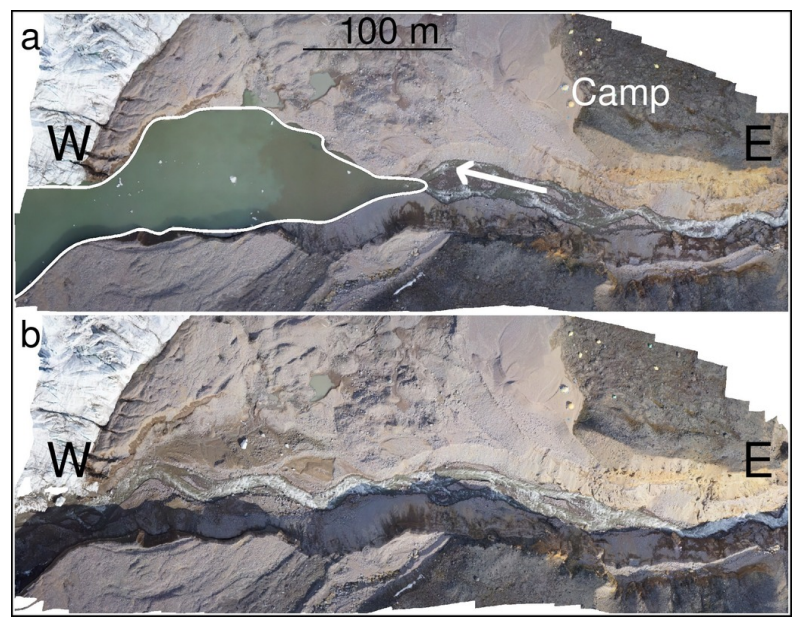

Figure 3: Ortho-images of the river next to the campsite (Fig. 2) taken shortly before (panel a, July 6, 14:37 UTC) and shortly after (panel b, July 7, 14:07 UTC) the lake outburst. The white arrow indicates the flow direction of the river. In a), the lake outline has been drawn in to facilitate the comparison of the two panels.

particular; take-off and landing are not possible when the wind is stronger than $20 \mathrm{~km} / \mathrm{h}$, and manual input from a pilot is required when the wind exceeds $10 \mathrm{~km} / \mathrm{h}$. The Firefly6 is a Y6-like VTOL, which is characterized by i) two motors in the back used for hovering, and ii) four motors in the front used for hovering or flying forward after the motors rotate by 90 degrees to produce forward thrust, see Fig. 4.

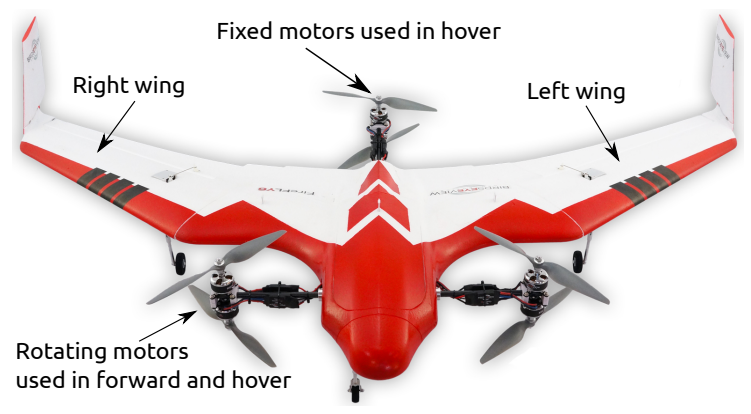

Figure 4: Vertical Take-Off and Landing UAV "Firefly6" (wingspan $1520 \mathrm{~mm}$ ). The forward axis supports four motors, which can rotate by $90^{\circ}$ for flight transition between a hexacopter and a fixed-wing. 
The Firefly 6 has a wingspan of roughly 1.5 $\mathrm{m}$ and is made from expanded polypropylene foam, see Fig. 4. We equipped our model with $\mathrm{a} \sim 400 \mathrm{~g}$ camera, which was attached to the underside of the fuselage. During takeoff and landing, the camera was protected by three retractable landing gears. Our Firefly6 was loaded with two $6 \mathrm{~S}$ Litihum Polymer batteries $(22.2 \mathrm{~V}, 10 \mathrm{Ah})$. In this configuration, which is the heaviest possible (i.e., $4 \mathrm{~kg}$ in total), it was able to climb $400 \mathrm{~m}$ and fly approximately $40 \mathrm{~km}$, assuming that the flying time in hover configuration - the most power consuming mode - was reduced as much as possible, leaving the battery voltage well above $21 \mathrm{~V}$ to prevent any battery damage. Our Firefly6 was commanded by the "Pixhawk" open-source autopilot (https : //pixhawk.org/) running with an ad-hoc firmware, which is a hybrid version of the "arduplane" and the "arducopter" firmwares (http://ardupilot.org/ardupilot/). The whole system costs approximately USD 3000.

The UAV flew 22 times between the 6th and the 18th of July, roughly every 12 hours (around 12.00 and 24:00 UTC), following a pre-programmed sequence of waypoints located over the river and at the two extremities of the glacier, so that the calving front was covered by four parallel flight lines, see Fig. 2 . (Note that Bowdoin Glacier is located above the Arctic Circle and had uninterrupted sunshine during our campaign.) Although our VTOL UAV could have been operated in full autonomous mode, we always flew it manually during the take-off and landing stages in order to achieve an optimal control, and switched to autonomous mode only when the Firefly 6 was already in forward configuration. The VTOL was launched directly from our camp, which featured a small, flat area made of sand and gravel suitable for taking-off and landing. Each flight was sequenced as follows:

1. manual vertical take-off in hover config- uration,

2. manual transition to forward configuration,

3. switch to automatic mode to follow programmed waypoints,

4. altitude gain $(100 \mathrm{~m})$ and survey of the river,

5. altitude gain $(300 \mathrm{~m})$ while flying to the calving front,

6. survey of the calving front by four parallel flight lines,

7. return to the campsite while losing altitude,

8. take manual control and transition to hover configuration,

9. manual vertical landing in hover configuration.

Flight data including horizontal position, relative altitude, ground and air speeds, state of battery charge, levelling, and heading, were monitored via a telemetry system during the entire flight from the camp. This monitoring data proved to be useful on one occasion to trigger an early return-to-launch after wind conditions severely deteriorated in the course of one flight.

\subsection{Photogrammetry by Structure-from- Motion}

Our VTOL UAV carried a Sony Alpha 6000 camera, which has a 24 megapixel sensor, captures JPEG format images in the visible light range, and was equipped with a $16 \mathrm{~mm}$ fixed lens. During the surveys the camera was set to aperture priority, with a shutter speed of $1 / 2500 \mathrm{~s}$, an ISO value of 400 , and autofocus. For each flight, the UAV flew 25 $\mathrm{km}$ at an altitude of approximately $400 \mathrm{~m}$ above ground, and collected roughly 300 overlapping pictures with a resolution of $10 \mathrm{~cm}$ per pixel, and a footprint of $600 \mathrm{~m} \mathrm{x} 400$ m. The pictures overlapped at $95 \%$ in the flight direction and $70 \%$ in the wing direction. For accurate georeferencing, $70 \mathrm{~cm} \mathrm{x} 70 \mathrm{~cm}$ 
squared Ground Control Points (GCP) were installed on both sides of the glacier and on the moving glacier surface, see Fig. 2. The position of the moving GCPs was recorded repeatedly using a DGPS positioning system so that their absolute positions during each flight was linearly approximated. The pictures of each flight were post-processed by Structure-from-Motion using Agisoft PhotoScan software (http://www.agisoft.com/). As a result, a $10 \mathrm{~cm}$ resolution georeferenced digital surface model and ortho-image of the river and the calving front (covering approximately $3 \mathrm{~km}^{2}$ ) was reconstructed with a horizontal error of $10-20 \mathrm{~cm}$ (or 1-2 pixels) for each of the 22 flights, see Figs. 3 and 5 .

\subsection{Feature tracking for the ice flow}

A variety of image-matching methods exist for the purpose of deriving glacier surface velocities. In this study we used the Matlab toolbox ImGRAFT (http://imgraft. glaciology.net/) to derive horizontal velocities, which is achieved by the means of template matching (Messerli and Grinsted, 2015). Thus we were able to infer 19 ice displacement fields by processing Digital Surface Models (DSM) (Ryan et al., 2015) pairwise using 24 hour intervals, see Figs. 5 and 7a. Note that we did not process $12-\mathrm{h}$-spaced data (although available), as the ice displacement during this short time period was found to be too small relative to the pixel size to achieve an accurate result.

\subsection{Mapping of the plume footprints}

The UAV ortho-images also served to map the footprint of each plume at the ocean surface in order to compute their areas, see Fig. 7. Here, we defined the footprint as being the plume-induced iceberg-free zone, which is easy to identify visually, see Fig. 6, top panels.

\subsection{Particle Image Velocimetry for plume} water flow

While flying over the calving front, the UAV captured a sequence of aerial images (spaced by $\sim 1-2 \mathrm{~s}$ ) of each plume, see Figs. $2 \mathrm{c}$ and 6 , bottom panels. With an image footprint of $600 \mathrm{~m} \mathrm{x} 400 \mathrm{~m}$, each plume was captured in from 1 to 10 pictures, which show the fast water flow as reflected in the motion of suspended sediments arising from subglacial drainage, see Fig. 1. The Particle Image Velocimetry (PIV) method (Weitbrecht et al., 2002) was used to infer the plume water surface displacement field from UAV images. Based on a cross-correlation technique between two subsequent images, the PIV method gives the average motion of rasterized subimage patterns. The PIV technique recently proved its worth for determining river flow velocity cased on UAV airborne imagery (Detert et al., 2017). For this study, we used the MATLAB-based open-source software PIVlab (Thielicke and Stamhuis, 2014). Prior to the PIV analysis, it was necessary to pre-process the aerial images for georeferencing purposes, for masking unwanted features, and for image enhancement. As this pre-processing requires some manual work, we applied the PIV only to the largest plume (called \#1) and to three 24-h-spaced flights (on July 15, at 23:43 UTC, on July 16 at 23:48 UTC, and on July 18 at 00:50 UTC). After applying the PIV, each displacement vector field was median-filtered to remove any artifacts, see results in Figs. 9 and 11. In order to distinguish the area of radially diverging flow of the plume (i.e., the smooth part characterized by small gradients) from the rest, we applied the Euclidean norm of the gradient of the horizontal velocity components $\left(u_{x}, u_{y}\right)$ :

$$
\sqrt{\sum_{i=x, y} \sum_{j=x, y}\left|\frac{\partial u_{i}}{\partial x_{j}}\right|^{2}}
$$




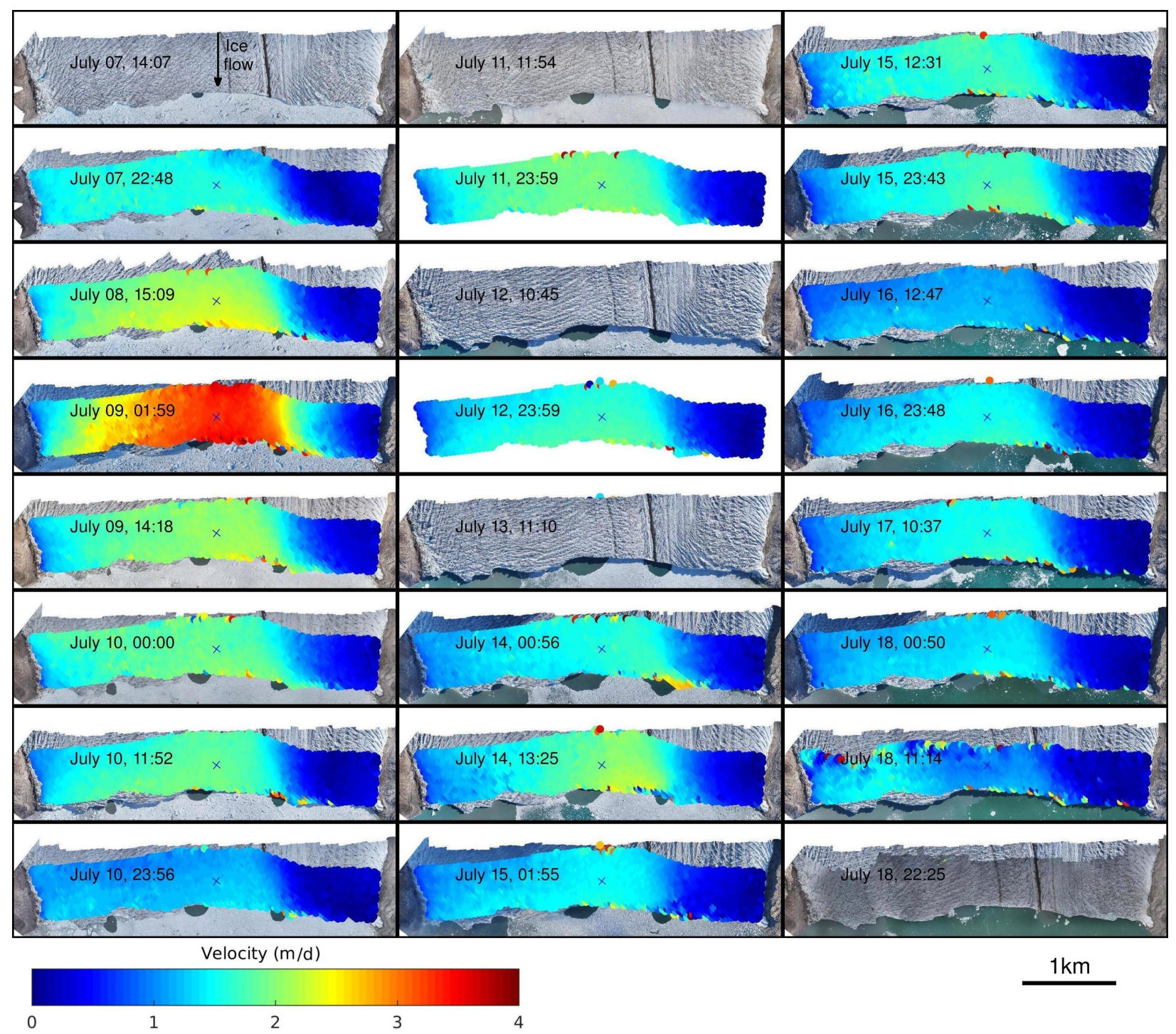

Figure 5: Ortho-images and ice surface velocity fields of the calving front of Bowdoin Glacier every 12 hours from July 7 to July 19, 2016. The time shown is the take-off time (in UTC) of the VTOL, which was the basis of each ortho-image. By contrast, the superimposed velocity field was inferred from the previous and subsequent digital surface models, i.e., those taken approximately 12 hours before and after the indicated time. Note that two ortho-images (July 11 and 12) are missing as there were no UAV flights at that time. In the absence of these data, three velocity fields (on July 10,11, and 12) are also missing. The ortho-images facilitated the mapping of the plume footprints at the ocean surface in order to determine their areas in Fig. 7. Plumes are more visible in the presence of ice mélange. The blue cross indicates the POS1 position, where a DGPS - similar to the one described in (Sugiyama et al., 2015) - was installed to record the ice speed at this location with a sub-centimeter accuracy level during the field campaign period.

see Fig. 10. Lastly, we computed the mean velocity fields (averaged over the tens of UAV pictures covering the plume area while flying over it, see Fig. 6, bottom panel) to compare the plume activities on July 15, 16 and 18, see Fig. 12. Further details about the image pre-processing and the application of PIV are given in Appendix A. 


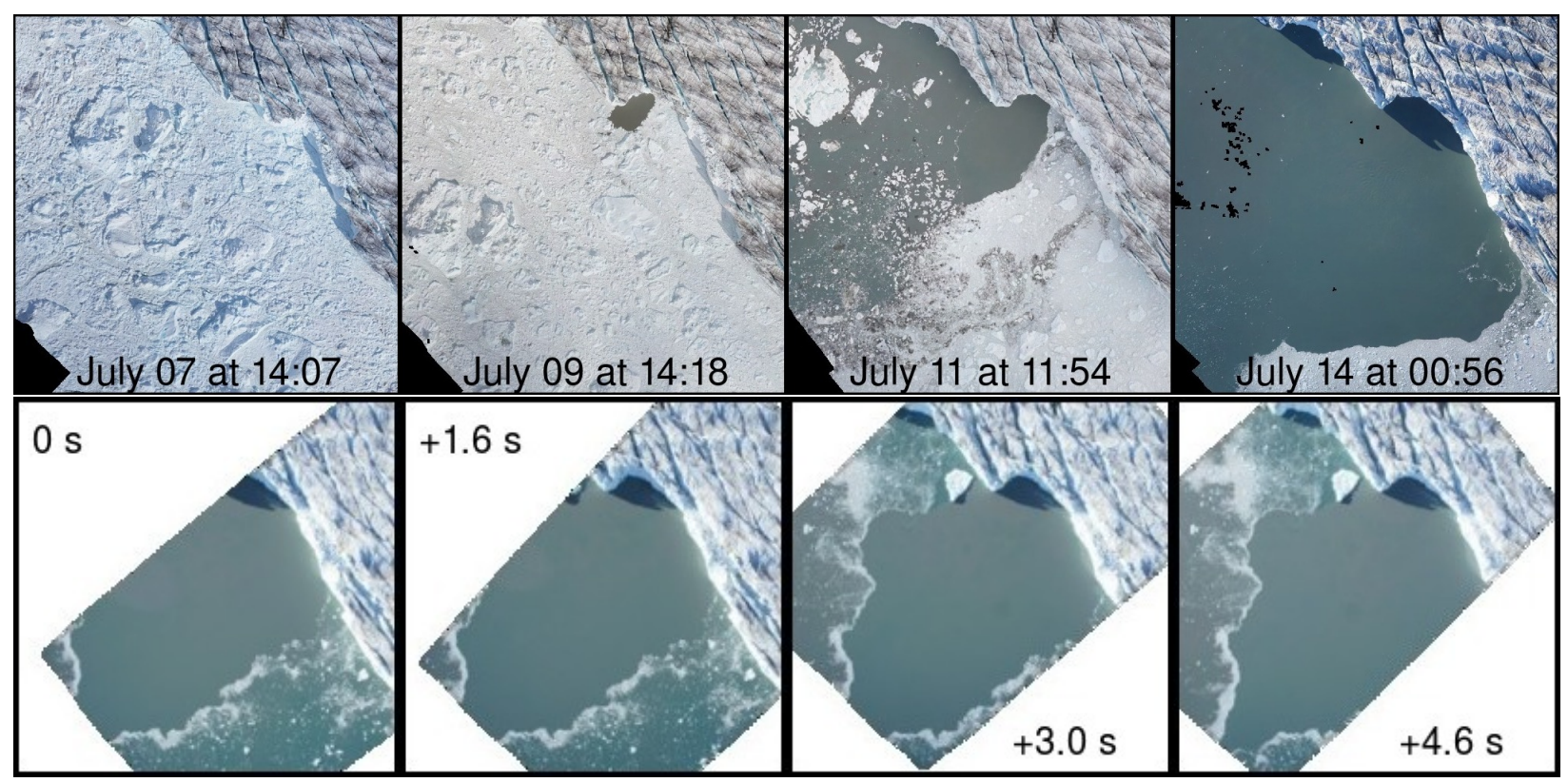

Figure 6: Top: Approximately 48-h-spaced ortho-images showing the appearance and the evolution of plume $\# 1$, whose extent can be identified easily by the presence of icebergs, sea ice or ice mélange. Bottom: Example of orthorectified aerial images of plume \#1 taken sequentially when the UAV flew over the first line on July 15, 23:43, and used in Particle Image Velocimetry (PIV) analysis. Because of its large extent at that time, plume $\# 1$ is visible in its entirety on only a few images.

\subsection{Melt rates of Bowdoin, Obelisk, and Mir- ror Glaciers}

Additionally to UAV data, melt measurements taken from July 3 to July 31 on the Qaanaaq Ice Cap and Bowdoin Glacier (Sugiyama et al., 2016b; Tsutaki et al., 2017) were used to estimate of the average melt rate for each of the three basins (Bowdoin, Obelisk, and Mirror). To this end, we applied a melt-rate altitude relationship interpolated linearly from these measurements to the ice surface of each drainage basin, see Fig. 2a.

\section{Results}

Figures 5, 7, and 8 bring together our results in terms of glacier ortho-images and inferred velocity fields with a 12-h-frequency, and therefore allow us to monitor various features of Bowdoin Glacier, including calving activities, ice flow speed-up, or plume footprint. By contrast, Figs. 9, 10, 11, and 12 display the PIV results of the surface flow of plume \#1.

\subsection{Calving front position}

A comparison of the first (July 7) and the last (July 18) ortho-images in Fig. 5 reveals that the position of the calving front remained mostly unchanged, i.e., no significant iceberg detachment (or calving event) occurred between these two dates. In contrast, a huge fracture opened during the same period one year before, and collapsed into a large-scale calving event about two weeks later (Jouvet et al., 2017).

\subsection{Surface ice flow speed-up}

For verification purposes, the UAV-inferred surface ice velocities are first compared to 24$h$ averaged reference velocities measured by cm-accurate differential GPS at POS1 position (see Fig. 5), which is located at the middle of the glacier, see Fig. 7a. Over the 19 
inferred velocities at POS1, 8, 12, and 16 are less than $0.1,0.25$ and $0.5 \mathrm{~m} \mathrm{~d}^{-1}$ close to the reference velocities, respectively. The standard deviation of $0.22 \mathrm{~m} \mathrm{~d}^{-1}$, i.e., $10-15 \%$ of the total ice motion. These errors are due mainly to the photogrammetry and featuretracking.

The time period from July 7 to 19 featured a remarkable two-day-long speed-up event, with a peak up to $2.6 \mathrm{~m} \mathrm{~d}^{-1}$ during the night of July 8 to 9 , while the rest of the period showed fairly constant velocities (near $1.5 \mathrm{~m}$ $\mathrm{d}^{-1}$ ), see Figs. 5 and 7 . Figure 8 confirms that the ice velocities almost doubled during the speed-up, but also shows that the acceleration was not uniform but more pronounced on the south-east side than on the north-west side of the calving front.

\subsection{Break-up of the ice mélange}

The ortho-images of Figure 5 also reveal the complete break-up of the ice mélange a mixture of sea ice, icebergs, and snow between July 7 and July 18. Indeed, initial evidence of break-up was seen on July 11 on the north-west side of the front. Yet the disappearance of ice mélange did not continue to the other side. Instead, it diminished until it disaggregated totally on July 15 .

\subsection{Appearance and widening of plumes}

Three plumes were identified (Fig. 5) at the ocean surface next to the calving front of Bowdoin Glacier and above the outflow of subglacial drainage channels to the ocean (Fig. 1). For the sake of clarity, we numbered them from the north-west to the southeast sides of the calving front, see Fig. 2, bottom panel. As a result, our data capture the appearance and the widening of the three plumes (Fig. 7b). Only plume \#2 had already appeared on July 7 (Fig. 5), and was still rather small at that time (approximately $4000 \mathrm{~m}^{2}$, see Fig. 7). Then plume \#3 appeared on July 7 , and plume \#1 appeared
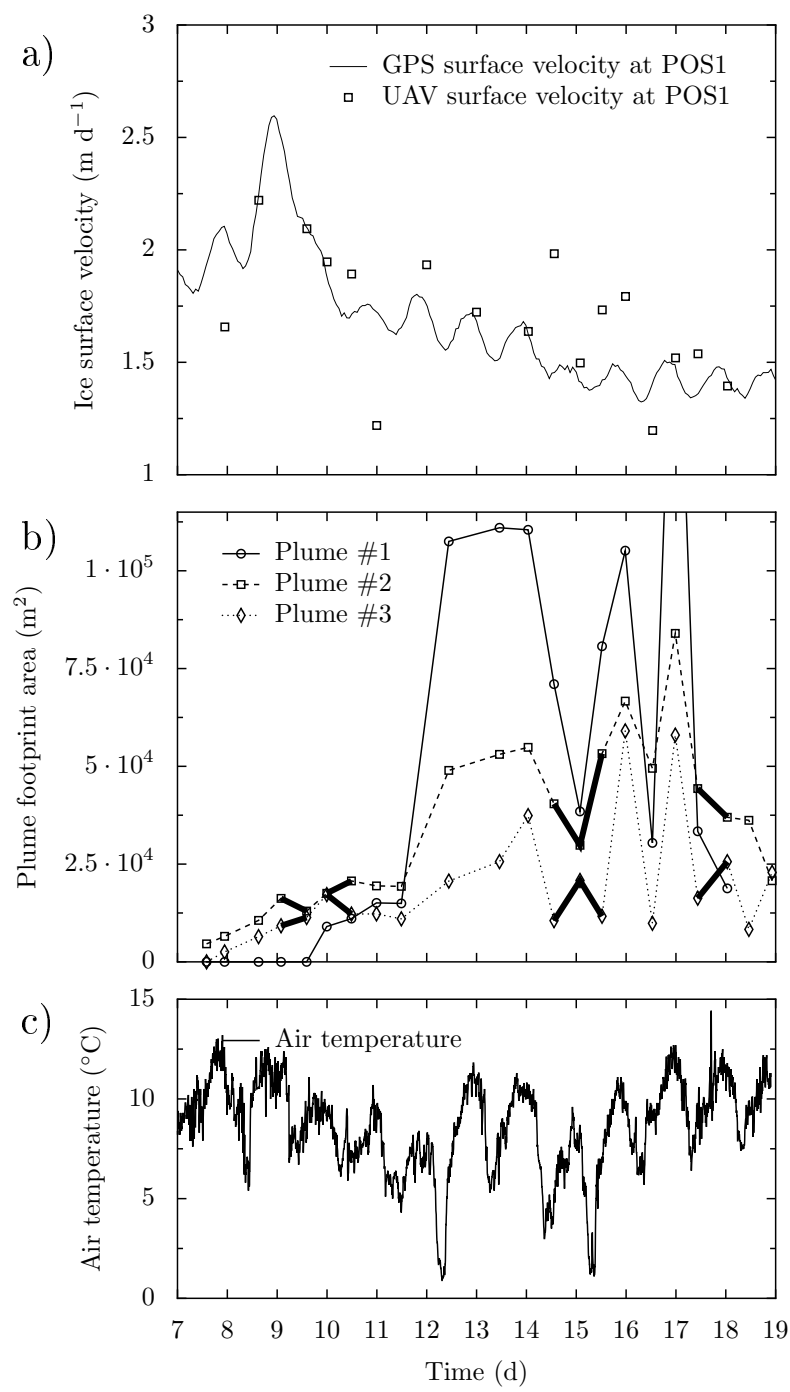

Figure 7: a) 24-h averaged GPS and UAV-inferred velocities at POS1 from July 7 to July 19. b) Area of each meltwater plume surface footprint defined in Fig. 2, and inferred from the ortho-images of Fig. 5. Anti-correlations between plumes $\# 2$ and $\# 3$ are highlighted in bold. c) Air temperature recorded at the camp by an automatic weather station (Sugiyama et al., 2016a).

two days later (Fig. 5). While the three grew regularly until July 11, a sudden widening occurred on July 12 (especially plume \#1). The three plumes remained active until July 15 before decreasing quickly in intensity and attaining sizes similar to those from before July 


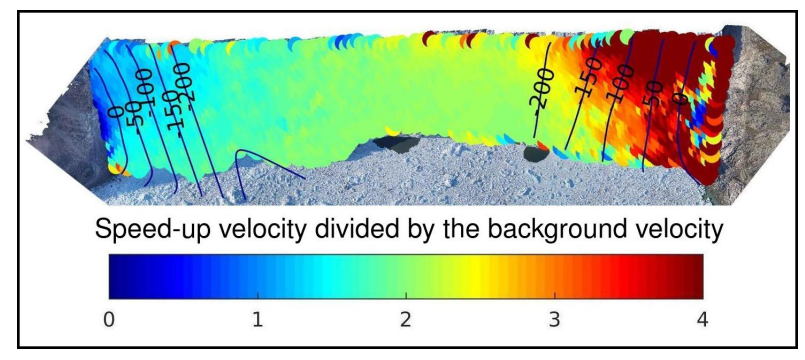

Figure 8: Speed-up velocity (computed from July 8, 15:09 to July 9, 14:18 DSMs) divided by the background velocity (computed from July 11, 11:54 to July 16, 12:47 DSMs). In addition, we drew the contour lines of the bedrock inferred by groundpenetrating radar (Asaji, 2018).

12 (Fig. 7). Afterwards, two short-lived high peak events occurred at around 00:00 UTC on July 16 and 17, see Fig. 7b. In addition, variations in surface areas of plumes \#2 and \#3 were found to be anti-correlated five times. An individual analysis of the activity of each plume reveals a strong imbalance along the calving front. Indeed, their footprints on the ocean surface are much more pronounced on the north-west side (plume \#1) than on the south-east side (plume \#3), see Fig. 7b.

\subsection{Plume water flow}

Figure 9 shows results of the PIV analysis. PIV appears to be an efficient method for deriving plume surface flow. The inferredvelocity field of plume \#1 (Fig. 9a) shows three easily identifiable zones: i) a smooth pattern moving radially (at 1-2 $\mathrm{m} \mathrm{s}^{-1}$ ) from the presumed source at the glacier front towards the ocean, ii) a noisy pattern over the rest of the iceberg-free zone - earlier identified as being the footprint of the plume, and iii) a nearly immobile zone outside the plume footprint, characterized by the presence of sea ice, mélange, and / or icebergs. Fig. 10 shows that the smooth and radially diverging flow area of the plume (i.e., the active part indicated by small gradients) and the chaotic flow area (i.e., the inactive part indicated by large gradients) always remained stable at short time scales. However, the velocity magnitudes of the plume were changing rapidly (the recorded velocities can be doubled within a couple of seconds) with heterogeneous patterns, as shown in Fig. 11. When comparing the plume activities on July 15, 16 and 18, see Fig. 12, we find that the size of the smooth pattern part of the plume $(2.8$, 3.5 and $1.8 \times 10^{4} \mathrm{~m}^{2}$, respectively) changed consistently (although non-linearly) with its visually inferred plume footprint (10.5, 19.3 and $1.8 \times 10^{4} \mathrm{~m}^{2}$, respectively). Additionally, we observe a correlation between size and flow velocity magnitude of the active plume when comparing the two extreme cases (July 16 and 18), while this is less obvious when comparing it with July 15.

\subsection{Drainage of the ice-dammed marginal lake}

A river flowed into an ice-marginal lake on July 6 , which was near to the campsite, see Fig. 3. At that time, the river was diverted along the glacier edge towards the front, indicating that the glacier was an efficient dam, see Fig. 2, middle panel. Yet the lake was emptied 24 hours later as shown in Fig. 3. In fact, the drainage was directly observed from the camp: it started at approximately 23:30 UTC on July 6, and lasted roughly 2:30 hours (E. Podolskiy, personal communication). From looking at the difference between the two elevation models inferred by UAV photogrammetry before and after the lake outburst (Fig. 3), we estimate the volume of the ice-marginal lake at $1.9 \times 10^{5} \mathrm{~m}^{3}$ of water. More precisely, we computed 1.45 $\times 10^{5} \mathrm{~m}^{3}$ for the $75 \%$ visible area of the lake, the $25 \%$ remainder being outside of the monitored zone, see Fig. 3.

\subsection{Daily melt rate estimates}

Following the method described in Section 3.6 , we estimated the mean daily melt rate of 

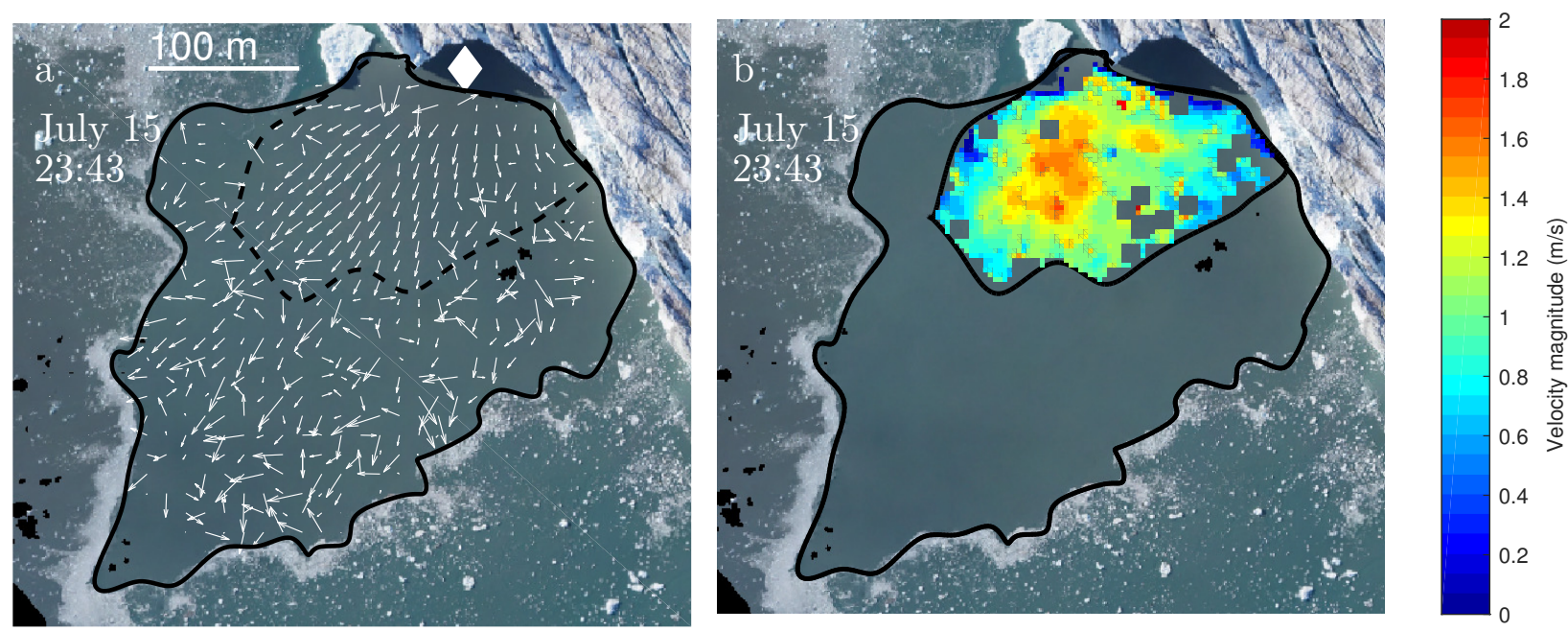

Figure 9: Panel a shows the instant water surface velocity vector field of plume \#1 (Fig. 2) inferred by PIV from two subsequent UAV images (Fig. 6, bottom panel) taken when flying the first line over the calving front on July 15 at 23:43 UTC, while panel b shows the magnitude of the velocity where the flow has a smooth pattern. The dashed line on panel a delimits the smooth pattern area (active plume), while the diamond symbol indicates the likely location of the source of the plume.
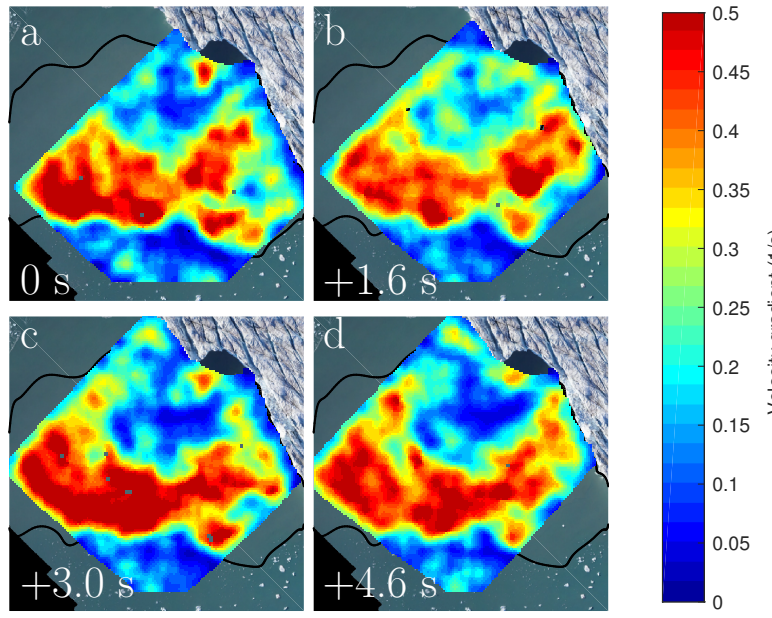

Figure 10: Euclidean norm of the velocity gradient (after being smoothed) defined by Eq. (1) of successive fields of plume \#1 for the flight operated on July 16 at 23:48 UTC.

the Bowdoin, Obelisk, and Mirror Glaciers, at approximately $4.4 \times 10^{6} \mathrm{~m}^{3}, 1.4 \times 10^{6} \mathrm{~m}^{3}$, and $0.6 \times 10^{6} \mathrm{~m}^{3}$ of water, respectively.

\section{Discussion}

\subsection{The July 9 speed-up event}

The speed-up of tidewater glaciers in Greenland has been reported numerous times at seasonal scale in the literature (Zwally et al., 2002; Joughin et al., 2004; Howat et al., 2005). For instance, the speed-up event at Bowdoin Glacier on July 9th is comparable to the mini-surge event observed on Ryder Glacier described in Joughin et al. (1996), even though the former occurred over a much shorter time period (two days rather than several weeks). Relatively few studies show evidence of high-amplitude ice speed-ups at daily and subdaily time scales, as this requires in-situ observations. In a previous study, Sugiyama et al. (2015) showed (using continuous GPS stations on ice) that Bowdoin regularly experiences short-lived accelerations in response to heavy precipitation or high air temperatures, both causing a surplus of water subglacially, with the result that the basal friction and speed-up of the ice flow are diminished. Sugiyama et al. (2011) showed 

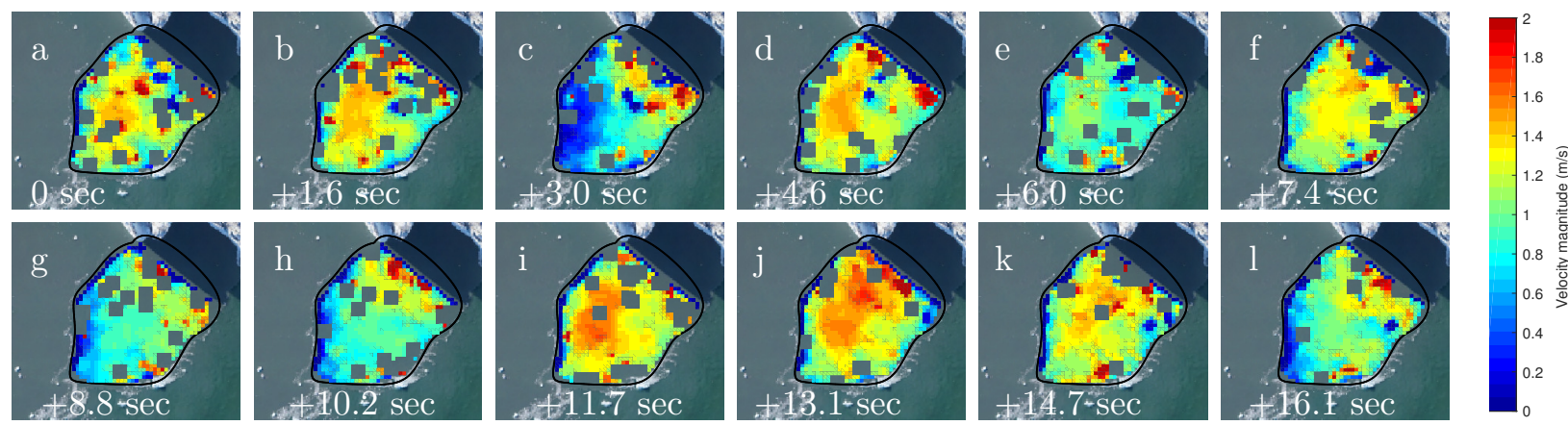

Figure 11: Magnitudes of the water velocities inferred from 13 subsequent 1-2 s spaced UAV images taken when flying the first line over plume \#1 on July 18 at 00:50 UTC.
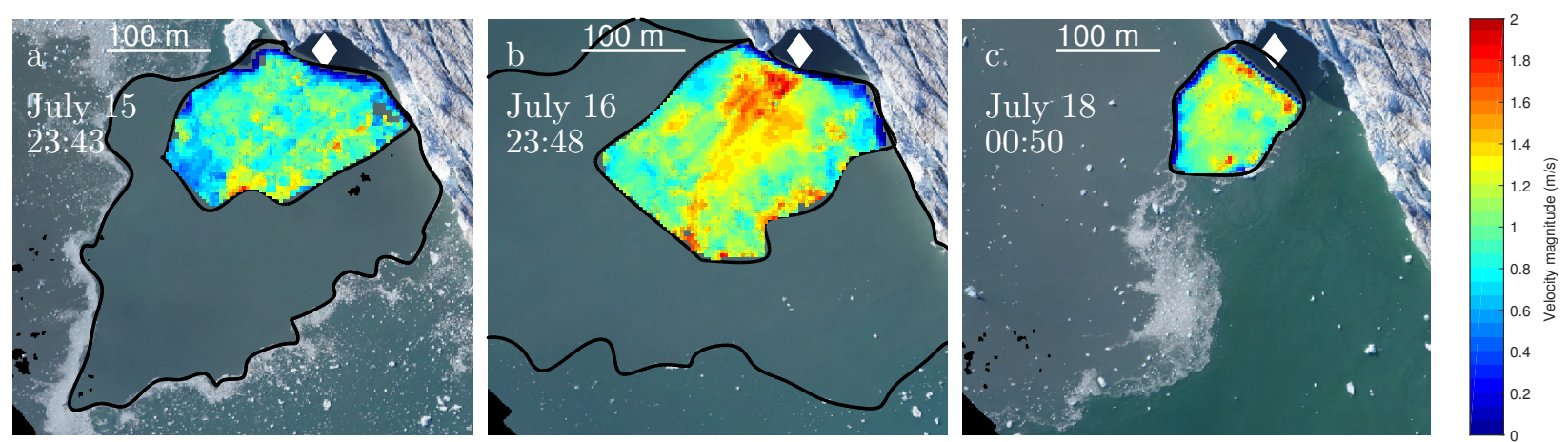

Figure 12: Magnitudes of the water velocities of plume \#1 (averaged over the tens of fields inferred by PIV from successive UAV images covering the plume) on July 15, 16 and 18, respectively. The continuous lines delimit the active plume area and the visually inferred footprint.

that change in basal water pressure by a few percent can drive nearly $40 \%$ of the variations in the ice flow. To our knowledge, the record of a short-lived, high-amplitude, and non-tidal speed-up event of similar duration to the one of July 9 one has been replicated only on Store Glacier, as reported in Doyle et al. (2018). The latter coincided with a high peak in the subglacial water pressure resulting from heavy rainfalls and high melt rate episodes shortly before.

Here, the July 9 event happened after a few days of relatively high air temperatures (Fig. 7c) without precipitation (not shown), and coincided with the opening of plume \#1, and the widening of plumes \#2 and \#3 (Fig. 7b). We assume that the warm temperatures - or the outburst of a supraglacial lake (Kjeldsen et al., 2014) - caused the subglacial hydrological network to be highly pressurized, thus leading, on the one hand, to the ice speed-up, and on the other, to channel formation, and the appearance of the largest plume. However, the lake drainage event (Section 4.6), which occurred 2 days before the main speedup event recorded was likely coincidental. Indeed, this sudden additional water flux $(75 \times$ $10^{3} \mathrm{~m}^{3} \mathrm{~h}^{-1}$ ) in the subglacial drainage system for 2.5 hours was probably too low compared to the meltwater discharge $\left(265 \times 10^{3} \mathrm{~m}^{3}\right.$ $\mathrm{h}^{-1}$ ) for causing any significant acceleration of the ice flow. Additionally, any resulting acceleration would have occurred within the next 24 hours considering the relatively short 
distance between the lake and the glacier front (approximatively $2 \mathrm{~km}$ ), and the slowest recorded times of subglacial transport of meltwater (Werder, 2009).

\subsection{Enhanced speed-up over shallow bedrock}

The ice velocity fields displayed in Figure 5 show a systematic and remarkable highly sheared zone located upstream of the calving front on the south-east side of Bowdoin Glacier (Jouvet et al., 2017). This is the result of a strong variation between slow/resistive lateral and fast/floating central flow. This flow pattern is very likely due to an asymmetric bedrock shape (Fig. 8) in the transect direction (very shallow on the southeast side). Figure 8 also shows that the July 9 speed-up event was significantly more pronounced over the shallow zone than over the rest of the calving front. Here we assume that the ice flow is more sensitive to an increase in the englacial water level where the bedrock is shallow than where it is deep, as the increase in the flotation ratio (ice pressure divided by water pressure) - which is a key driver of the basal motion (e.g., Budd et al., 1984) - is higher. Therefore, the enhanced speed-up observed on the south-east side of the calving front (Fig. 8) can be interpreted as an indication of shallow bedrock topography.

\subsection{Origin of plumes}

The location of the three plumes along the front, and of the drainage basins suggests that plumes $\# 1, \# 2$, and \#3 have their origins in the Bowdoin, Obelisk, and Mirror drainage basins, respectively, see Fig. 2. This hypothesis is corroborated by a good fit between the relative contributions of each basin in terms of melt and of each plume footprint area. Indeed, the mean daily melt rate of the Bowdoin, Obelisk, and Mirror Glaciers represents $69 \%, 22 \%$, and $9 \%$ of the total, respectively, based on the estimates found in Sec- tion 4.7. On the other hand, the footprint of plumes $\# 1$, \#2, and \#3 represented roughly $54 \%, 31 \%$, and $15 \%$ of all plumes on average from July 12 to July 16, see Fig. 7b.

There is other evidence that plume \#3 most likely originates at Mirror Glacier. First, plumes \#1 and \#2 were always found in phase, while plumes \#2 and \#3 were found five times anti-correlated (Fig. 7b), a discrepancy that can be explained by the different predominant orientations of each basin (Bowdoin and Olelisk are oriented southsouthwest, while Mirror is oriented west), causing a variety of melting regimes (Hock, 1999). Second, plume \#3 appeared approximately 24 hours after the outburst of a marginal lake draining the meltwater of Mirror Glacier and located next to the campsite, see Figs. 2, 3, and 5. This drainage was likely caused by the formation of a new subglacial conduit, with the consequence of drying the original river bed along the glacier edge, as reported in field observations, see Fig. 2, middle panel. Therefore, the outburst event must have connected the discharge of Mirror Glacier with the channel of plume $\# 3$, and triggered its appearance at the ocean surface. Additionally, the connection between the two is corroborated by the bedrock topography, which descends gently from the southeast side towards the middle of the glacier, the first minimum coinciding with plume \#3 (Fig. 8).

\subsection{Dynamics of plume \#1}

The manual mapping of each plume (Section 3.4) is an imperfect indicator of each plume's activity. Indeed, the plume footprint was constrained by the presence of ice mélange, preventing it from growing until July 11, see Figs. 6 and 5, top panels. Once the ice mélange was gone, the footprint was found to be 3 to 5 times larger than before, providing a better reflection of the intensity 
of the plume, without, however, clearly indicating the limits of the active part.

In contrast, PIV provides a much more detailed picture of the complex water flow (Fig. $9)$. The PIV analysis of plume \#1 shows surface water expanding smoothly and radially from a presumable source next to the glacier front (indicated by the diamond symbol) towards the ocean over a disk of various radii $\sim$ $100 \mathrm{~m} \pm 50 \mathrm{~m}$, see Fig. 9a. As expected, the highest velocities were localized at the center of the plume indicating that water particles slow down when moving outwards, see Fig. 9b. Most importantly, the smooth flow pattern did not cover the entire plume footprint - as visually inferred from UAV orthoimages of the iceberg-free area - but only a fraction of it (termed "active"), the rest being characterized by chaotic flow, see Fig. 9a. Such a pattern is typical of upwelling buoyant plumes resulting from the gravitational convection of cold fresh water into warm and salty ocean water, (e.g., Jenkins, 2011; Carroll et al., 2015; Mankoff et al., 2016; Slater et al., 2017b). Here it is assumed that the smooth flow pattern captured by PIV corresponds to the active plume area, while the chaotic flow pattern indicates a failure of PIV due to the absence of tracers/suspended sediments in this zone, the latter having been entrained by downward currents towards the neutral buoyancy level, see Fig. 1. Supporting this assumption, this dual regime is clearly visible on the hydrographic measurements of a plume of another Greenlandic calving glacier, Saqqarliup Sermia, published by Mankoff et al. (2016).

Our results show that the active plume area remains fairly stable within a couple of seconds (Fig. 10); however, the velocities might change rapidly (being doubled, see Fig. 11), indicating pulsating vertical water jets and the unsteady nature of the plume flow. At the daily time scale, the area of the active plume could change significantly (being mul- tiplied by a factor of 3 within 24 hours, see Fig. 12). The active plume area coincided with its visually identified footprint on July 18, but differed substantially by a factor of up to 5 from the previous 48 hours, indicating that only PIV can determine reliably the real size of the active plume. Additionally, a comparison of panels $b$ and $c$ (the two extreme plume configurations) in Fig. 12 shows that the peak of velocities (reached at the center of the pool) increases in line with the plume size. This illustrates that stronger flow is needed to shape a large plume.

The mean daily melt rate of Bowdoin Glacier in July - estimated at $4.4 \times 10^{6} \mathrm{~m}^{3}$ - corresponds to a mean water discharge of approximately $51 \mathrm{~m}^{3} \mathrm{~s}^{-1}$ for plume \#1. This configuration is comparable with the results from plume model 'MITgcm' given in Fig. 4e of Slater et al. (2017b), which predicts the radius of the plume at $\sim 100 \mathrm{~m}$ and the surface velocity at $\sim 1 \mathrm{~m} \mathrm{~s}^{-1}$ for a discharge of 50 $\mathrm{m}^{3} \mathrm{~s}^{-1}$ and with a 250-m-deep calving front (similar to Bowdoin). This rough comparison should be understood in a broad sense as the discharge of fresh water can certainly be estimated more accurately (e.g., following a PDD approach as in Slater et al. (2017b)), and many parameters such as temperature or salinity are still needed to further compare our PIV-inferred data to model results, a task going beyond the scope of this study.

\subsection{Impacts of plume \#1 on submarine melt- ing and calving}

It is well known that the presence of a plume along the glacier front can strongly enhance the submarine melting (Motyka et al., 2003; Kimura et al., 2014). Here the speed-up event of July 9 indicates that the meltwater discharge must have been high, and the subglacial melt rate maximal, causing the plumes to erode the glacier front at that time (Slater et al., 2017a). The plume-induced submarine melting rates were most likely in the range of 
the estimated rates from hydrographic data for glaciers in Greenland, e.g., from 0.7 to 12 $\mathrm{m} \mathrm{d}^{-1}$ (Motyka et al., 2003; Rignot et al., 2010), and most likely at the high end of this range for plume $\# 1$ in the vicinity of its source.

In support of this hypothesis, a calving event occurred approximately one day before the opening of plume \#1, causing an apparent triangular notch in the glacier front, exactly where the plume formed (compare the first two top panels of Fig. 6). Here it is assumed that the glacier calved by the process of undercutting (after plume \#1 eroded the glacier front), similar to the calving pattern observed at Store Glacier by Chauché et al. (2014). In contrast, the two other plumes were located along a straight calving front, indicating that their subglacial melting rates and discharges were in likelihood significantly lower than for plume \#1.

\section{Conclusions and perspectives}

In this study, a Vertical Take-Off and Landing (VTOL) UAV was used for the first time in a glaciological application. Our UAV has a flight range of roughly $40 \mathrm{~km}$, and can take off and land vertically in confined areas. It is therefore the ideal tool for conducting recurrent glacier surveys and for monitoring fast-changing features such as ice flow, lake drainage, calving or plume activities. We have demonstrated here its suitability for mapping approximately $3 \mathrm{~km}^{2}$ with a $10-\mathrm{cm}$ resolution, provided moderate wind conditions. The flight range of multicopters is conditioned to new developments in light highcapacity batteries. Nevertheless, wide fixedwing UAVs require flat and large terrain in order to be able to land, and their full automation remains somewhat cumbersome, especially in polar regions. For these reasons, VTOLs possess only a great potential for expanding the typical range of UAVs for novice users.

We used Structure-from-Motion photogrammetry and feature-tracking techniques to infer 22 high-resolution ortho-images and 19 ice flow velocity fields at the calving front from aerial images taken by VTOL UAV for 12 days in July 2016. In addition, for the first time, we used Particle Image Velocimetry (PIV) to infer information about plume surface water flow from successive UAV images. From these data, our findings were:

i) One two-day-long speed-up event (up to $170 \%$ ) occurred during a relatively warm period, and prior to the appearance of a major plume, showing that this event was likely triggered by an increase in meltwater supply to the subglacial drainage system, or the collapse of a supraglacial lake.

ii) Spatial variations in the speed-up reveal a correlation with the bedrock topography: the speed-up is more pronounced where the bedrock is the shallowest.

iii) The origin of each plume can be estimated by matching the relative activity of each plume to the estimated melt of each drainage basin.

iv) The drainage of a marginal lake with approximately $1.9 \times 10^{5} \mathrm{~m}^{3}$ of water triggered the opening of the third plume, but is most likely unrelated to the observed speed-up event.

v) The PIV method is efficient for determining the plume water flow and for accurately localizing the active part of the plume, which was discovered to be between 1 to 5 times smaller than its visual footprint, characterized by an icebergfree zone. 
vi) The magnitudes of the plume surface water velocities show pulsating vertical jets at the scale of a second, evidence of the unsteady nature of the plume flow.

vii) The size of the active plume can vary by a factor of 3 within a day.

viii) Before it was visible, the first plume - fed by a highly pressurized subglacial hydrological network - caused the foot of the glacier front to melt rapidly, with the result of triggering a calving event by undercutting.

We have demonstrated the ability of the combined UAV / PIV method to infer the dynamics of the visible part of a plume at a short time scale and at high resolution, such as no other remote sensing technique can achieve. PIV can give a very detailed picture of the plume dynamics (flow magnitudes and directions, extent and variability) at the ocean surface. Future studies should therefore address the combining of PIV data with non-steady plume models capable of reproducing pulsating jets, in order to infer the water run-off and the melt rate of submarine glacier fronts (e.g., Kimura et al., 2014; Carroll et al., 2015).

\section{Acknowledgements}

The authors wish to acknowledge Martin Funk for giving helpful comments on the manuscript, Evgeniy Podolskiy for information on the lake drainage, Mauro Werder for helpful discussions on the impact of the lake outburst on the subglacial hydrology of Bowdoin Glacier, and Adam Sloan and Rene Roy from BirdsEyeView Aerobotics for their support in setting up the Firefly6 UAV. This research was funded by the Swiss National Science Foundation, Grants 200020-169558 and 200021-153179/1, and Dr. Wolfram Frost, ETH Zurich Foundation. Our thanks are extended also to S. Braun-Clarke for proofreading the English.

\section{Author contributions}

GJ designed the study and wrote the paper with support from JS, MK, and MD. GJ and YW operated the VTOL UAV during the 2016 field campaign. JS measured the moving GCPs on the moraine by DGPS. YW processed the aerial images by Structurefrom-Motion photogrammetry. GJ processed the resulting digital elevation models with ImGRAFT. MK processed the orthorectified UAV images with PIVlab under the supervision of MD. JS processed Sentinel-2A satellite images with SentinelFlow. DS and SS provided the GPS ice velocities, groundpenetrating radar profiles of the bedrock, air temperature and melt data used in the paper. All authors contributed to the paper.

\section{A. The application of PIV to infer plume water flow: detailed work- flow}

Here we describe the step-by-step workflow for inferring water velocity fields using PIV from UAV aerial images of a plume, as illustrated in Figure 6, bottom panels.

The first step was the projection of each UAV image onto the sea surface in order to infer comparable georeferenced and orthorectified images. However, due to coloration homogeneity in the area of the plume, the Structure-from-Motion technique could not resolve this area to produce a Digital Elevation Model (DEM), as needed for the projection. To overcome this issue, a flat DEM with a fixed altitude corresponding to the sea level at the time of the flight was introduced. The sea level was determined based on the ellipsoidal height of the sea $(11.42 \mathrm{~m}$ at this location) and a kinematic GPS survey of the ocean level from 17:11 to 18:05 on July 12 in 2013. Additionally, the sea level was adjusted to account for the tides from measurements taken every 5 minutes between July 15 
and July 24 near the front of Bowdoin Glacier (data from M. Minowa).

The second step consisted in applying some masks and filters to all images prior to the PIV analysis. This typically included i) the replacement of 8 bit JPEG images (used by the Structure-from-Motion) by 16 bit RAW images in order to use all the information available ; ii) the masking of unwanted features such as birds, glaciers, icebergs, sea ice or shaded areas ; iii) the conversion to gray scale ; iv) the application of a local Laplacian filter (via the locallapfilt MATLAB function) ; and v) noise reduction via a Wiener filter with a window of $3 \mathrm{px} \times 3 \mathrm{px}$ (via the wiener2 MATLAB function).

The final and main step was to apply the PIVlab software (Thielicke and Stamhuis, 2014) to the pre-processed set of images. Here the PIV algorithm uses direct Fourier to transform the correlation with multiple passes and deforming windows onto a final grid of $64 \mathrm{px} \times 64 \mathrm{px}$ window sizes and $50 \%$ overlap. Larger window sizes led to less accurate spatial results, while smaller window sizes resulted in too much noise. Finally, with a $64 \mathrm{px} \times 64 \mathrm{px}$ window size and a pixel resolution of approximately $10 \mathrm{~cm}$, this led to a discrete surface displacement field with a resolution of $6.4 \mathrm{~m}$.

After the PIV analysis, the results were median-filtered with the medfilt2 MATLAB function to attenuate any artifacts resulting from the PIV vector computation, and the displacement vector fields were re-interpreted into velocity vector fields after normalizing by the time interval between the two images.

\section{References}

Asaji, I., 2018. Influence of ocean bed geometry on the front variations of bowdoin glacier, northwestern greenland. Master thesis, Hokkaido University.
Bartholomaus, T. C., Stearns, L. A., Sutherland, D. A., Shroyer, E. L., Nash, J. D., Walker, R. T., Catania, G., Felikson, D., Carroll, D., Fried, M. J., et al., 2016. Contrasts in the response of adjacent fjords and glaciers to ice-sheet surface melt in west Greenland. Annals of Glaciology 57 (73), 25-38.

Bartholomew, I., Nienow, P., Sole, A., Mair, D., Cowton, T., King, M. A., 2012. Shortterm variability in greenland ice sheet motion forced by time-varying meltwater drainage: Implications for the relationship between subglacial drainage system behavior and ice velocity. Journal of Geophysical Research: Earth Surface 117 (F3).

Bhardwaj, A., Sam, L., Akanksha, MartÃynTorres, F. J., Kumar, R., 2016. UAVs as remote sensing platform in glaciology: Present applications and future prospects. Remote Sensing of Environment 175, 196 204.

Budd, W. F., Jenssen, D., Smith, I. N., 1984. A three-dimensional time-dependent model of the West Antarctic Ice Sheet. Annals of Glaciology 5, 29-36.

Carroll, D., Sutherland, D., Shroyer, E., Nash, D., Catania, G., Stearns, L., 2015. Modeling turbulent subglacial meltwater plumes: Implications for fjord-scale buoyancy-driven circulation. Journal of Physical Oceanography, 2169-2185.

Chauché, N., Hubbard, A., Gascard, J.-C., Box, J., Bates, R., Koppes, M., Sole, A., Christoffersen, P., Patton, H., 2014. Iceocean interaction and calving front morphology at two west Greenland tidewater outlet glaciers. The Cryosphere 8 (4), 1457-1468.

Chu, V. W., Smith, L. C., Rennermalm, A. K., Forster, R. R., Box, J. E., Reehy, N., 
2009. Sediment plume response to surface melting and supraglacial lake drainages on the Greenland Ice Sheet. Journal of Glaciology 55 (194), 1072-1082.

Detert, M., Johnson, E., Weitbrecht, V., 2017. Proof of concept for low cost and non contact synoptic airborne river flow measurements. International Journal of Remote Sensing 38, 2780-2807.

Dinniman, M. S., Asay-Davis, X. S., GaltonFenzi, B. K., Holland, P. R., Jenkins, A., Timmermann, R., 2016. Modeling ice shelf/ocean interaction in Antarctica: A review. Oceanography 29 (4), 144-153.

Doyle, S., Hubbard, B., Christoffersen, P., Young, T. J., Hofstede, C., Bougamont, M., Box, J., Hubbard, A., 2018. Physical conditions of fast glacier flow: 1. measurements from boreholes drilled to the bed of store glacier, west Greenland. Journal of Geophysical Research: Earth Surface.

Gagliardini, O., Zwinger, T., Gillet-Chaulet, F., Durand, G., Favier, L., de Fleurian, B., Greve, R., Malinen, M., Martín, C., Råback, P., Ruokolainen, J., Sacchettini, M., Schäfer, M., Seddik, H., Thies, J., 2013. Capabilities and performance of Elmer/ice, a new-generation ice sheet model. Geoscientific Model Development 6 (4), 1299-1318.

Heid, T., Kääb, A., 2012. Evaluation of existing image matching methods for deriving glacier surface displacements globally from optical satellite imagery. Remote Sensing of Environment 118, 339 - 355.

Hock, R., 1999. A distributed temperatureindex ice- and snowmelt model including potential direct solar radiation. Journal of Glaciology 45 (149), 101-111.
How, P., Benn, D. I., Hulton, N. R. J., Hubbard, B., Luckman, A., Sevestre, H., van Pelt, W. J. J., Lindbäck, K., Kohler, J., Boot, W., 2017. Rapidly changing subglacial hydrological pathways at a tidewater glacier revealed through simultaneous observations of water pressure, supraglacial lakes, meltwater plumes and surface velocities. The Cryosphere 11 (6), 2691-2710.

URL https://www.the-cryosphere. net/11/2691/2017/

Howat, I. M., Joughin, I., Tulaczyk, S., Gogineni, S., 2005. Rapid retreat and acceleration of Helheim Glacier, east Greenland. Geophysical Research Letters 32 (22).

Immerzeel, W., Kraaijenbrink, P., Shea, J., Shrestha, A., Pellicciotti, F., Bierkens, M., de Jong, S., 2014. High-resolution monitoring of himalayan glacier dynamics using unmanned aerial vehicles. Remote Sensing of Environment 150, $93-103$.

Jenkins, A., 2011. Convection-driven melting near grounding lines of ice shelves and tidewater glaciers. Journal of Physical Oceanography 41, 2279-2293.

Joughin, I., Abdalati, W., Fahnestock, M., 2004. Large fluctuations in speed on Greenland's Jakobshavn Isbrae glacier. Nature 432 (7017), 608.

Joughin, I., Smith, B., Howat, I., Scambos, T., Moon, T., 2010. Greenland flow variability from ice-sheet-wide velocity mapping. Journal of Glaciology 56, 415-430, doi:10.3189/002214310792447734.

Joughin, I., Tulaczyk, S., Fahnestock, M., Kwok, R., 1996. A mini-surge on the Ryder Glacier, Greenland, observed by satellite radar interferometry. Science 274 (5285), 228-230. 
Jouvet, G., Weidmann, Y., Seguinot, J., Funk, M., Abe, T., Sakakibara, D., Seddik, H., Sugiyama, S., 2017. Initiation of a major calving event on the Bowdoin Glacier captured by UAV photogrammetry. The Cryosphere 11 (2), 911-921.

Kanna, N., Sugiyama, S., Ohashi, Y., Sakakibara, D., Fukamachi, Y., Nomura, D., 2018. Upwelling of macronutrients and dissolved inorganic carbon by a subglacial freshwater driven plume in bowdoin fjord, northwestern greenland. Journal of Geophysical Research: Biogeosciences 123 (5), 1666-1682.

URL https://agupubs.onlinelibrary. wiley.com/doi/abs/10.1029/ 2017 JG004248

Kimura, S., Holland, P. R., Jenkins, A., Piggott, M., 2014. The effect of meltwater plumes on the melting of a vertical glacier face. Journal of Physical Oceanography 44 (12), 3099-3117.

Kjeldsen, K. K., Mortensen, J., Bendtsen, J., Petersen, D., Lennert, K., Rysgaard, S., 2014. Ice-dammed lake drainage cools and raises surface salinities in a tidewater outlet glacier fjord, west Greenland. Journal of Geophysical Research: Earth Surface 119 (6), 1310-1321.

Mankoff, K., Straneo, F., Cenedese, C., Das, S., Richards, C., Singh, H., 2016. Structure and dynamics of a subglacial discharge plume in a Greenlandic fjord. J. Geophys. Res. Oceans 121, 8670-8688.

Messerli, A., Grinsted, A., 2015. Image georectification and feature tracking toolbox: ImGRAFT. Geoscientific Instrumentation, Methods and Data Systems 4 (1), 23-34.

Morlighem, M., Seroussi, H., Larour, E., Rignot, E., 2013. Inversion of basal friction in antarctica using exact and incomplete adjoints of a higher-order model. Journal of Geophysical Research: Earth Surface 118 (3), 1746-1753.

Motyka, R. J., Dryer, W. P., Amundson, J., Truffer, M., Fahnestock, M., 2013. Rapid submarine melting driven by subglacial discharge, leconte glacier, alaska. Geophysical Research Letters 40, 1-6.

Motyka, R. J., Hunter, L., Echelmeyer, K. A., Connor, C., 2003. Submarine melting at the terminus of a temperate tidewater glacier, LeConte Glacier, Alaska, USA. Annals of Glaciology 36, 57-65.

Murray, T., Nettles, M., Selmes, N., Cathles, L. M., Burton, J. C., James, T. D., Edwards, S., Martin, I., O'Farrell, T., Aspey, R., Rutt, I., Baugé, T., 2015. Reverse glacier motion during iceberg calving and the cause of glacial earthquakes. Science.

Pętlicki, M., Kinnard, C., 2016. Calving of fuerza aérea glacier (greenwich island, antarctica) observed with terrestrial laser scanning and continuous video monitoring. Journal of Glaciology 62 (235), 835-846.

Pfeffer, T., 2007. A simple mechanism for irreversible tidewater glacier retreat. Journal of Geophysical Research 112 (F03S25).

Podolskiy, E. A., Sugiyama, S., Funk, M., Walter, F., Genco, R., Tsutaki, S., Minowa, M., Ripepe, M., 2016. Tide-modulated ice flow variations drive seismicity near the calving front of Bowdoin Glacier, Greenland. Geophysical Research Letters 43 (5), 2036-2044, 2016GL067743.

Pritchard, H. D., Arthern, R. J., Vaughan, D. G., Edwards, L. A., 2009. Extensive dynamic thinning on the margins of the Greenland and Antarctic ice sheets. Nature 461, doi:10.1038/nature08471. 
Riesen, P., Strozzi, T., Bauder, A., Wiesmann, A., Funk, M., 2011. Short-term surface ice motion variations measured with a ground-based portable real aperture radar interferometer. Journal of Glaciology 57 (201), 53-60.

Rignot, E., Koppes, M., Velicogna, I., 2010. Rapid submarine melting of the calving faces of West Greenland glaciers. Nature Geoscience 3, 187-191, dOI: 10.1038/NGEO765.

Ryan, J. C., Hubbard, A. L., Box, J. E., Todd, J., Christoffersen, P., Carr, J. R., Holt, T. O., Snooke, N., 2015. UAV photogrammetry and Structure-from-Motion to assess calving dynamics at Store Glacier, a large outlet draining the Greenland Ice Sheet. The Cryosphere 9 (1), 1-11.

Sakakibara, D., Sugiyama, S., 2018. Ice front and flow speed variations of marineterminating outlet glaciers along the coast of prudhoe land, northwestern greenland. Journal of Glaciology 64 (244), 300-310.

Slater, D., Nienow, P., Goldberg, D., Cowton, T., Sole, A., 2017a. A model for tidewater glacier undercutting by submarine melting. Geophysical Research Letters 44 (5), 23602368.

Slater, D., Nienow, P., Sole, A., Cowton, T., Mottram, R., Langen, P., Mair, D., 2017b. Spatially distributed runoff at the grounding line of a large Greenlandic tidewater glacier inferred from plume modelling. Journal of Glaciology 63, 309-323.

Stevens, L. A., Straneo, F., Das, S. B., Plueddemann, A. J., Kukulya, A. L., Morlighem, M., 2016. Linking glacially modified waters to catchment-scale subglacial discharge using autonomous underwater vehicle observations. The Cryosphere 10 (1), 417-432.
URL https://www.the-cryosphere. net/10/417/2016/

Sugiyama, S., Sakakibara, D., Asaji, I., 2016a. Meteorological data of bowdoin glacier, greenland in july 2016 . Tech. rep.

URL

https://ads.nipr.ac.jp/ dataset/A20170418-001

Sugiyama, S., Sakakibara, D., Kanna, N., Ohashi, Y., Asaji, I., 2016b. Summer surface mass balance of Bowdoin Glacier, Greenland in 2016. Tech. rep.

URL https://ads.nipr.ac.jp/ dataset/A20170517-002

Sugiyama, S., Sakakibara, D., Tsutaki, S., Maruyama, M., Sawagaki, T., 2015. Glacier dynamics near the calving front of Bowdoin Glacier, northwestern Greenland. Journal of Glaciology 61, 223-232.

Sugiyama, S., Skvarca, P., Naito, N., Enomoto, H., Tsutaki, S., Tone, K., Marinsek, S., Aniya, M., 2011. Ice speed of a calving glacier modulated by small fluctuations in basal water pressure. Nature Geoscience 4 (9), 597.

Thielicke, W., Stamhuis, E., 2014. PIVlab towards user-friendly, affordable and accurate digital particle image velocimetry in MATLAB. Journal of Open Research Software 2(1), e30.

Tsutaki, S., Sugiyama, S., Sakakibara, D., Aoki, T., Niwano, M., 07 2017. Surface mass balance, ice velocity and nearsurface ice temperature on Qaanaaq Ice Cap, northwestern Greenland, from 2012 to 2016. Annals of Glaciology 58, 181-192.

Tsutaki, S., Sugiyama, S., Sakakibara, D., Sawagaki, T., 2016. Surface elevation changes during 2007-2013 on Bowdoin and Tugto Glaciers, northwestern Greenland. Journal of Glaciology, in press 62 (236). 
Weitbrecht, V., Kühn, G., Jirka, G., 2002. Large scale PIV-measurements at the surface of shallow water flows. Flow Measurement and Instrumentation 13 (5), 237-245.

Werder, M., 2009. Dye tracing and modelling jökulhlaups. Ph.D. thesis, ETH Zurich.

Zwally, H. J., Abdalati, W., Herring, T., Larson, K., Saba, J., Steffen, K., 2002. Surface melt-induced acceleration of Greenland icesheet flow. Science 297 (5579), 218-222. 